\title{
The evaluation of team lifting on physical work demands and workload in ironworkers
}

\author{
Henk F. van der Molen ${ }^{1 \mathrm{a}, \mathrm{b}}$, Steven Visser ${ }^{\mathrm{a}}$, P. Paul F.M. Kuijer ${ }^{\mathrm{a}}$, Gert Faber ${ }^{\mathrm{c}, \mathrm{de}, \mathrm{e}}$, \\ Marco J.M. Hoozemans ${ }^{c}$, Jaap H. van Dieën ${ }^{c}$, Monique H.W. Frings-Dresen ${ }^{a}$ \\ ${ }^{a}$ Coronel Institute of Occupational Health, Academic Medical Center, University of Amsterdam, PO Box 22700, \\ 1100 DE Amsterdam, the Netherlands \\ ${ }^{\mathrm{b}}$ Arbouw, Ceintuurbaan 2, 3847 LG Harderwijk, the Netherlands \\ ${ }^{c}$ Research Institute MOVE, Faculty of Human Movement Sciences, VU University, Van der Boechorststraat 9 , \\ 1081 BT, Amsterdam, The Netherlands \\ ${ }^{d}$ Department of Environmental Health, Harvard School of Public Health, 665 Huntington Avenue, Boston, MA \\ 02115, USA \\ ${ }^{e}$ Liberty Mutual Research Institute for Safety, 71 Frankland Road, Hopkinton, MA 01748, USA
}

\begin{abstract}
Lifting and carrying heavy loads occur frequently among ironworkers and result in high prevalence and incidence rates of low back complaints, injuries and work-disability. From a health perspective, little information is available on the effect of team lifting on work demands and workload. Therefore, the objective of this study was to compare the effects of team lifting of maximally $50 \mathrm{~kg}$ by two ironworkers (T50) with team lifting of maximally $100 \mathrm{~kg}$ by four ironworkers (T100). This study combined a field and laboratory study with the following outcome measures: duration and frequency of tasks and activities, energetic workload, perceived discomfort and maximal compression forces (Fc peak) on the low back. The physical work demands and workload of an individual iron worker during manual handling of rebar materials of $100 \mathrm{~kg}$ with four workers did not differ from the manual handling of rebar materials of $50 \mathrm{~kg}$ with two workers, with the exception of low back discomfort and Fc peak. The biomechanical workload of the low back exceeded for both T50 and T100 the NIOSH threshold limit of $3400 \mathrm{~N}$. Therefore, mechanical transport or other effective design solutions should be considered to reduce the biomechanical workload of the low back and the accompanying health risks among iron workers.
\end{abstract}

Keywords: Team lifting, Physical work demands, Workload, Prevention, Construction work.

\section{Introduction}

Lifting and carrying heavy loads occur frequently among ironworkers [1] and is associated with high prevalence and incidence rates of low back complaints, injuries and work-disability [2]. The Dutch labour inspectorate allows manual handling of rebar materials up to maximally $50 \mathrm{~kg}$ with two iron workers. Employers' organisations and unions, however, realized that mechanical transport of frequently used rebar materials up to $100 \mathrm{~kg}$ is not always preventa-

\footnotetext{
${ }^{1}$ Corresponding author. E-mail: h.f.vandermolen@amc.nl
}

ble at construction sites, due to technical, economical or organisational limitations. From a health perspective, little information is available on the effect of team lifting on work demands and workload.

Therefore, the objective of this study was to establish the effect of team lifting on work demands and workload among ironworkers. 


\section{Method}

A within-subjects $(n=10)$ controlled field study during full working days and an experimental laboratory study $(n=12)$ were performed to compare the effects of team lifting of maximally $50 \mathrm{~kg}$ by two persons (T50) with team lifting of maximally $100 \mathrm{~kg}$ by four persons (T100).

\subsection{Field study}

In the field study, the following outcomes were determined: duration and frequency of tasks and activities, energetic workload and perceived body region discomfort. The task demands were measured by means of systematic observations using the PalmTRAC system [3]. The energetic workload was determined through the percentage heart rate reserve (\%HRR). Perceived body region discomfort was measured using visual analogue scales.

In total, ten experienced ironworkers participated in the study: mean (SD) age, height, weight and years of work experience were 38 (7) years, $180(9) \mathrm{cm}, 81$ (13) $\mathrm{kg}$ and 17 (9) years, respectively.

\subsection{Laboratory study}

Maximum peak lumbar compression force (Fc peak) was calculated $[4,5]$ using a 3D dynamic biomechanical model and anthropometric, kinematic and ground-reaction force data of fourteen lifting and carrying conditions in a laboratory setting divided over two methods of team lifting [6, this proceedings]:

1 lifting and carrying a 50-kg load, two iron bars, in a team with one other ironworker (two-worker manual handling),

2 lifting and carrying a 100-kg load, an iron lattice, in a team with three other ironworkers (fourworker manual handling, e.g. see Fig. 1).

In total, twelve experienced ironworkers participated in the laboratory study: mean (SD) age, height, weight and years of work experience were 31 (8) years, $180(8) \mathrm{cm}, 80$ (13) $\mathrm{kg}$ and 11 (9) years, respectively. Five of them also participated in the field study.

\subsection{Statistics}

Differences in mean duration and frequency of tasks and activities, energetic workload, local discomfort and Fc peak between T50 en T100 were tested with ANOVA for repeated measures. All tests were carried out using SPSS (Statistical Product and Service Solutions 16.0). A significant difference was defined as $\mathrm{p}<0.05$.

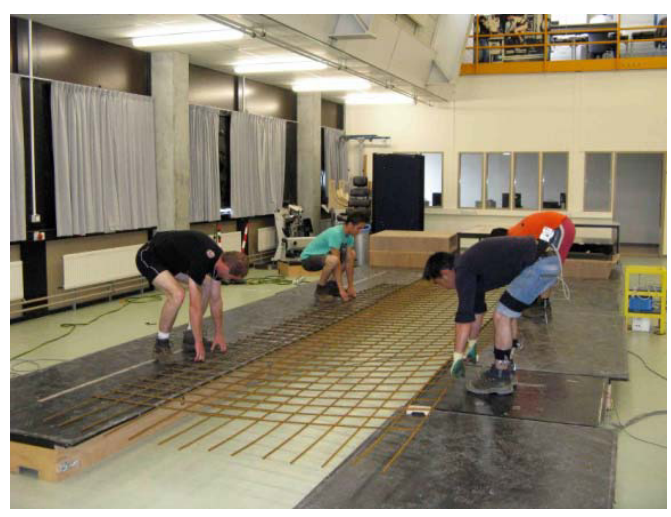

Figure 1. Four ironworkers lifting a 100-kg lattice

\section{Results}

Total work time, duration of tasks, duration of lifting and carrying, and energetic workload did not significantly differ between T50 and T100.

Low back discomfort at the end of the workday was significantly higher for the condition of T100 (VAS score 24 (SD 23)) compared to T50 (VAS score $8(\mathrm{SD} 12))$ on a scale from $0-100(\mathrm{p}=0.016)$.

In the laboratory, compared to the T50 lifting conditions, the T100 lifting conditions resulted in a lower Fc peak during the lifting tasks but in a higher Fc peak during carrying tasks.

For T50 and T100, the average maximal lumbar compression forces during lifting from floor level were $5286 \mathrm{~N}$ (SD 831) and 4768N (SD 941), respectively. The average maximal lumbar compression forces during carrying while stepping over a $46 \mathrm{~cm}$ obstacle were 7471N (SD 993) and 7860N (SD 833), respectively. 


\section{Discussion}

The physical work demands and workload of an individual iron worker during manual handling of rebar materials of $100 \mathrm{~kg}$ with a total of four workers did not differ from the manual handling of rebar materials of $50 \mathrm{~kg}$ with a total of two workers, with the exception of perceived low back discomfort and Fc peak.

The biomechanical workload of the low back exceeded for both T50 and T100 the NIOSH threshold limit of $3400 \mathrm{~N}$ [7] during lifting as well as during carrying loads over obstacles.

Implementation of preventive measures like mechanical transport or other effective design solutions should be considered to reduce the biomechanical workload of the low back and the accompanying health risks among iron workers.

\section{References}

[1] Paquet V, Punnett L, Woskie S, Buchholz B. Reliable exposure assessment strategies for physical ergonomics stressors in construction and other non-routinized work. Ergonomics (2005), 48(9),1200-1219.

[2] ARBOUW. Bedrijfstakatlas 2010 (Amsterdam: Arbouw) Internet:

www.arbouw.nl/arbodienstverlener/tools/bedrijfstakatlas2010/

[3] Frings-Dresen MHW and Kuijer, PPFM. The TRAC-system: an observation method for analysing work demands at the workplace. Safety Science (1995), 21, 163-165.

[4] Kingma I, de Looze MP, Toussaint HM, Klijnsma HG \& Bruijnen TBM. Validation of a full body 3-D dynamic linked segment model. Hum. Mov. Sci. (1996), 15(6), 833-860.

[5] van Dieën JH \& Kingma I. Effects of antagonistic cocontraction on differences between electromyography based and optimization based estimates of spinal forces. Ergonomics (2005), 48(4), 411-426.

[6] Faber G, Visser S, van der Molen HF, Kuijer PPFM, Hoozemans MJM, van Dieën JH, Frings-Dresen MHW. Does team lifting increase the variability in peak lumbar compression in ironworkers? This proceedings.

[7] Waters TR, Putz-Anderson V, Garg A, Fine LJ. Revised NIOSH equation for the design and evaluation of manual lifting tasks. Ergonomics (1993), 36, 749-776. 